\title{
BMJ Global Health Interface of health and trade: a view point from health diplomacy
}

\author{
Haik Nikogosian, ${ }^{1}$ Ilona Kickbusch ${ }^{2}$
}

To cite: Nikogosian $\mathrm{H}$, Kickbusch I. Interface of health and trade: a view point from health diplomacy. BMJ Glob Health 2018;3:e000491. doi:10.1136/ bmjgh-2017-000491

Handling editor Seye Abimbola

Received 25 July 2017 Revised 17 October 2017 Accepted 22 October 2017

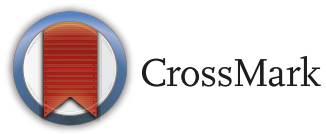

${ }^{1}$ World Health Organization Regional Office for Europe, Copenhagen, Denmark ${ }^{2}$ Global Health Center, Graduate Institute of International and Development Studies, Geneva, Switzerland

\section{Correspondence to}

Dr Haik Nikogosian, World Health Organization Regional Office for Europe, Copenhagen, Denmark;

nikogosian.haik@gmail.com
Traditionally, health diplomacy has been focused on achieving policy dialogue and consensus between states on important matters affecting and governing health. With the growing expansion of social, economic and political determinants of health, health diplomacy becomes equally focused on dialogue and coherence between different sectors. This makes the multisectoral dimension as an integral and equally important element of multilateral negotiations for health.

Another recent phenomenon is the legal nature of global health instruments aimed at and resulting from some of the international negotiations for health. The adoption of the WHO's first global treaty, the WHO Framework Convention on Tobacco Control (FCTC), ${ }^{1}$ and more recently its first Protocol, ${ }^{2}$ which is a new international treaty in its own right, have had a profound impact on strengthening the legal dimension of international health cooperation.

The above developments expand and strengthen the level and nature of interaction between health and the other key sectors. One such area is the interface between health and trade, a junction of growing complexity and interaction at both national and international levels.

This paper aims to demonstrate challenges and dynamics in the area of health and trade diplomacy, through a particular focus on tobacco control area where the recently adopted legal instruments marked significant changes and opportunities for intersectoral coherence and protecting health. Although the WHO FCTC was specifically negotiated to strengthen the action against tobacco, it is generally recognised that it shares broader governance space with other international agreements, including trade, human rights, customs and environment and that the tobacco control-trade policy nexus is not isolated, but rather part of a broader shift as countries consider the challenges of global governance generally. ${ }^{3}$

\section{Summary box}

- The paper analyses the growing and complex interface of health and trade from a viewpoint of health diplomacy and international legal instruments.

- The WHO Framework Convention on Tobacco Control (FCTC), WHO's first global treaty, had profoundly influenced and enriched trade and heath diplomacy through the legal strength it brought, along with the International Health Regulations (2005), to public health.

- The intensifying interaction of governments' legal obligations in trade and health triggers the need for and evidence of stronger policy coordination between the two sides.

- The negotiations and adoption of the WHO FCTC (and its first Protocol) represented unprecedented health diplomacy resulting in a highest level of international agreement for health; as the first health treaty experiences of the new century, they also represented a new approach in addressing the negative effects of globalisation and trade liberalisation on health.

- Multisectoral diplomacy and trade and health diplomacy in particular are at even higher demand when countries proceed to ratify and implement the agreed obligations on health in the complex environment of multiple legal frameworks and often competing agendas of governments.

From the viewpoint of health diplomacy, one apparent challenge in the intersection of health and trade is policy coordination between respective government sectors often pursuing different objectives and priorities; the need for such coordination and coherence has also been acknowledged at the international level. ${ }^{4}$ Another challenge is linked to the fact that while flexibilities to protect public health were incorporated in the World Trade Organisation (WTO) regime, the growing net of regional and bilateral trade and investment agreements (TIAs) weakens this determination and creates new obstacles; in addition, the strong corporate interests and 'power asymmetries' in how TIAs are negotiated and implemented, particularly the negotiating power imbalances between 
corporations and small states ${ }^{5}$ represent a notable challenge. In the case of implementing the WHO FCTC, challenges requiring protection of public health manifested in several instances, such as, for example, in the case of disputes initiated by several states in WTO questioning Australia's plain packaging legislation ${ }^{6}$ or in the case of legal claims made by Philip Morris against Australia and Uruguay under respective bilateral investment agreements. $^{7}$

In addition to WTO law and WHO FCTC, there have been other normative developments, ${ }^{8}$ in a form of 'softer' international instruments, aimed at policy coherence at the trade and health interface and promoting health, such as the WTO's 2001 Doha Declaration on the TRIPS agreement and public health, reaffirming and prioritising the agreed flexibilities to protect public health ${ }^{9}$ and the 2006 World Health Assembly Resolution on international trade and health ${ }^{4}$ addressing the issues of policy coherence in this intersection. In the meantime, the entry into force and implementation of the FCTC, as WHO's first global treaty, may have substantially changed the dynamics in the trade and health interface through the legal strength it brought, along with the International Health Regulations (2005), to public health.

In our view, there are several layers by which the intersection of health and trade can be seen in light of the first treaty experience in modern global health.

First, the WHO FCTC itself was developed in response to the growing influence of cross-border factors on health in the era of globalisation, including trade liberalisation, foreign direct investments, transnational marketing and illicit trade. It is widely seen that the Convention was the global response to the globalisation of the tobacco epidemic.

Second, the WHO FCTC elevated major public health action to the level of an international treaty. The interface of trade and health is therefore now regulated by legally binding obligations from both health and trade perspectives and not only from the trade perspective as it was before the adoption of the FCTC.

Third, there are fundamental factors suggesting that the two legal frameworks could be implemented without contradiction. It is important to note that the WHO FCTC expresses the determination of countries to give priority to their right to protect health. In turn, the WTO rules contain provisions in support of public health, such as exceptions and flexibilities to implement measures necessary to protect health (as long as such measures do not constitute 'arbitrary or unjustifiable discrimination between countries...or a disguised restriction on international trade').$^{10}$ In addition, those rules articulate the need to protect intellectual property rights 'in a manner conducive to social and economic welfare, and to a balance of rights and obligations', with a particular reference to public health. ${ }^{11}$ In summary, and also as stated in the United Nations Secretary General's report to Economic and Social Council, ${ }^{12}$ the WTO agreements and implementation of the WHO FCTC are not incompatible as long as the FCTC is implemented in a non-discriminatory fashion and for reasons of public health.

Fourth, the intensifying interaction of legal obligations in trade and health further underlined the need for policy coordination on both sides. Policymaking on health and trade is led by different ministries, generally with little interaction and even with little mutual awareness on relevant concerns, instruments and obligations; this has been manifested not only domestically but increasingly also in various international settings where the trade and health interaction takes place. Interestingly, the recent legal disputes launched in WTO and other international and national settings against governments introducing strong tobacco control measures such as plain packaging prompted increased dialogue and coordination between the two sectors. ${ }^{13}$ There is evidence of an increasing number of countries' trade representatives continuing the trend of the general support for tobacco control in meetings about international trade policy, including in WTO's Technical Barriers to Trade committee, using the language of trade policy, employing scientific evidence and citing the FCTC. ${ }^{3}$ However, such multisectoral diplomacy needs to improve also at the day-to-day level to ensure coherent implementation of countries' international obligations in both health and trade. It has also been argued that as trade policymaking is often embedded on larger political context, even strong health ministries, armed with good information and engaged in interministerial dialogue on trade, cannot guarantee a particular health-supportive outcome at international trade negotiations. ${ }^{14}$

Finally, the treaty approach had recently succeeded also in a related domain of international trade concerns with strong health implications, namely, illicit trade in tobacco products. Parties to the WHO FCTC negotiated, and adopted in 2012, the Protocol to Eliminate Illicit Trade in Tobacco Products - the first protocol to the FCTC and a new international treaty in its own right. The Protocol is yet another milestone in multilateral and multisectoral diplomacy for health, with the potential of substantial gains also beyond public health in areas such as trade, criminal justice, security and revenues.

Overall, in terms of health diplomacy at the intersection of health and trade, the unique contribution of the first treaty experience in modern public health is at least threefold:

- The development and adoption of the WHO FCTC and its first Protocol represented unprecedented health diplomacy resulting in a highest level of international agreement for health, with the participation of and consensus from a variety of non-health sectors, including trade.

- The Convention and its subsequent Protocol represent a new model for addressing the negative effects of globalisation and trade liberalisation on health, through negotiating and adopting legally binding 
global instruments to protect and promote health. The reality, nevertheless, is more complex; applying legal models will depend on political will and multilateral climate which might not be the same as when the WHO FCTC and International Health Regulations (2005), the first global health legal instruments of the 21st century, were negotiated. Further, prospects of costly legal claims such as those brought forward by the tobacco industry in recent years ${ }^{78}$ might deter the will of smaller states to take legal obligations in other health areas. The coming years will show whether countries apply legal approach in areas such as, for example, alcohol, processed foods or antimicrobial resistance (AMR).

- One of the greatest achievements of multilateral health diplomacy - the negotiations and adoption of WHO's first international treaty, and its Protocol, now raises the need for extensive multisectoral diplomacy to support the implementation (in the case of the Protocol the ratifications and entry into force) of agreed obligations, in the complex environment of multiple legal frameworks and often competing agendas of governments. The interface of health and trade will be one of the key areas for such diplomacy.

Acknowledgements Authors express their appreciation to Jonathan Liberman, McCabe Center on Law and Cancer, for his valuable comments during the preparation of the article.

Contributors Both authors contributed equally to the conception and design of this paper and drafting and revisiting it for important intellectual content.

Disclaimer The author(s) is(are) staff member(s) of the World Health Organization. The author(s) alone is(are) responsible for the views expressed in this publication and they do not necessarily represent the views, decisions or policies of the World Health Organization.

Competing interests None declared.

Provenance and peer review Not commissioned; externally peer reviewed.

Data sharing statement No additional data are available.

Open Access This is an open access article distributed under the terms of the Creative Commons Attribution-NonCommercial IGO License (CC BY-NC 3.0 IG0), which permits use, distribution, and reproduction for non-commercial purposes in any medium, provided the original work is properly cited. In any reproduction of this article there should not be any suggestion that WHO or this article endorse any specific organization or products. The use of the WHO logo is not permitted. This notice should be preserved along with the article's original URL. See:https:// creativecommons.org/licenses/by-nc/3.0/igo

CWorld Health Organization [2018].

\section{REFERENCES}

1. World Health Organization. WHO framework convention on tobacco control. Geneva: World Health Organization, 2003. http://www.who. int/fctc/text_download/en/ (accessed 4 Oct 2017).

2. WHO Framework Convention on Tobacco Control. Protocol to eliminate illicit trade in tobacco products. Geneva: World Health Organization, 2013. http://apps.who.int/iris/bitstream/10665/80873/ 1/9789241505246 eng.pdf?ua=1 (accessed 4 Oct 2017).

3. Drope J, Lencucha R. Evolving norms at the intersection of health and trade. J Health Polit Policy Law 2014;39:591-631.

4. World Health Assembly Resolution WHA59.26. International trade and health. 2006. http://apps.who.int/gb/ebwha/pdf_files/WHA59REC1/e/Resolutions-en.pdf (accessed 4 Oct 2017).

5. McNeill D, Birkbeck CD, Fukuda-Parr S, et al. Political origins of health inequities: trade and investment agreements. Lancet 2017;389:760-2.

6. World Trade Organization. DS467: Australia - certain measures concerning trademarks, geographical indications and other plain packaging requirements applicable to tobacco products and packaging. https://www.wto.org/english/tratop_e/dispu_e/cases_e/ ds467_e.htm (accessed 4 Oct 2017).

7. World Health Organization. Tobacco free initiative. http://www.who. int/tobacco/communications/highlights/international-tribunal-plainpackaging/en/ (accessed 4 Oct 2017).

8. World Health Organization. Confronting the tobacco epidemic in the new era of trade and investment liberalization: World Health Organization, 2012:128. ISBN 9789241503723.

9. World Trade Organization. The Doha Declaration on the TRIPS agreement and public health. https://www.wto.org/english/thewto_e/ minist_e/min01_e/mindecl_trips_e.htm (accessed 4 Oct 2017).

10. World Trade Organization. The general agreement on tariffs and trade (article 20). https://www.wto.org/english/docs_e/gattdocs_e. htm (accessed 4 Oct 2017).

11. World Trade Organization. Agreement on trade-related aspects of intellectual property rights (articles 7, 8). https://www.wto.org/ english/docs_e/legal_e/27-trips_01_e.htm (accessed 4 Oct 2017).

12. United Nations Economic and Social Council: Substantive session of 2012 New York, 2-27 July 2012. Ad hoc inter-agency task force on tobacco control, report of the Secretary-General. E/2012/70. 2012. http://www.who.int/tobacco/about/partners/un_taskforce/e201270. pdf?ua=1 (accessed 4 Oct 2017).

13. Welch C. JURIST - Professional Commentary. Tobacco plain packaging legislation. 2016. http://jurist.org/hotline/2016/01/craigwelch-tobacco-plain-packaging.php (accessed 4 Oct 2017).

14. Blouin C, Drager N. Policy coherence in trade and health. Smith R, eds. In: Trade and health; building a national strategy: World Health Organization. ISBN 9789241565035. 